\title{
A Taguchi Approach for Optimum Design of Proportional-Integral Controllers in Cascaded Control Scheme
}

\author{
Hany M. Hasanien, Senior Member, IEEE, and S. M. Muyeen, Senior Member, IEEE
}

\begin{abstract}
This study aims at resolving a specific problem in the area of renewable energy, energy storage systems, variable-speed drives, and flexible AC transmission system (FACTS) devices used in the electric power systems. The use of power conversion system (PCS) is very common in the aforementioned areas. A cascaded control scheme based on four proportional-integral (PI) controllers is widely used in the control of the PCS unit. Setting the parameters of the four cascaded PI controllers simultaneously is cumbersome, especially when the application is in the area of electrical power system which is difficult to express using a mathematical model or transfer function due to its nonlinear properties. This paper presents an optimum design procedure for the cascaded controller of the PCS unit using Taguchi method. To apply the design parameters obtained from Taguchi method, a renewable energy application is chosen where a variable-speed wind turbine generator system is connected to the power grid through two back-to-back PCS units. The effectiveness of the designed parameters using Taguchi method is then compared with that obtained using response surface methodology and genetic algorithm (RSM-GA) method under the grid fault condition.
\end{abstract}

Index Terms-Frequency converter, genetic algorithm, optimum design of proportional-integral (PI) controller, renewable energy, response surface methodology, Taguchi method, wind energy conversion system.

\section{INTRODUCTION}

$\mathbf{T}$ HE increase of oil price, concerns about climate, and the depletion of our natural resources have drawn much attention to the renewable energy technologies including wind, photovoltaic, tidal, marine current, etc. To extract the maximum power from these renewable energy sources, integrate, and transmit this extracted power to the existing power grid, the recent trend is to use different types of the power electronic converters which have bidirectional power flow control abilities. In some cases, different types of the energy storage systems are required to be integrated with the renewable energy systems which again use the power electronic converters. In the control of the renewable energy conversion systems including

Manuscript received April 24, 2012; revised May 09, 2012, July 10, 2012, and August 29, 2012; accepted October 08, 2012. Date of publication November 29, 2012

H. M. Hasanien is with the Electrical Power and Machines Department, Faculty of Engineering, Ain Shams University, 11517 Cairo, Egypt (e-mail: hanyhasanien@ieee.org).

S. M. Muyeen is with the Electrical Engineering Department, The Petroleum Institute, Abu Dhabi, UAE (e-mail: smmuyeen@pi.ac.ae). the power electronic converters, the use of cascaded scheme with proportional-integral (PI) controllers is a common engineering practice. Another potential application of this cascaded control is in flexible AC transmission system (FACTS) devices to resolve the power system stability relevant issues.

The classical PI controller has been utilized in many control applications including the aforementioned areas due to its robustness and it offers a wide stability margin [1]-[3]. However, setting the PI controller parameters is cumbersome, especially in industrial systems which have nonlinearities, high order, and delay time. Therefore, many methods have been used for fine tuning the PI controller parameters. One of these methods is Ziegler-Nichols method [2], [3]. Generally, it is difficult to achieve the best performance of the system using this method, where the design is widely depends on the designer experience for obtaining the best performance.

Besides, many artificial intelligence (AI) techniques such as neural network technique, fuzzy logic, and neuro-fuzzy system have been proposed to fine tune the PI controller parameters [4]-[6]. However, artificial neural networks suffer from the convergence time and the length of the training process. The fuzzy logic systems extensively depend on the experience of the designer in tuning the membership functions. Furthermore, evaluation and tuning of robust PI controllers have been proposed using a lambda tuning approach [7]. It is only specific for second-order non-minimum phase systems. The interval polynomial stability criterion and Lyapunov theorem have been introduced for designing the PI controller [8]. This method exhibits more and complex analysis in comparison with the other methods used in fine tuning the PI controller parameters. Recently, evolutionary computation techniques such as genetic algorithm (GA) and particle swarm optimization (PSO) have been applied to obtain an optimal design of a PI controller [9]-[14]. GA mainly depends on the concept of "survival of the fittest". The PSO is motivated by the social behavior of bird flocking and fish schooling. Although GA and PSO have great potentials to solve many optimization problems, they suffer from large memory capability and computational burden.

It is noted that there are some applications which are being treated as purely nonlinear such as the power systems and renewable energy systems. To find a precise mathematical model or transfer function for the individual components of the entire system is really difficult. For optimum design of cascaded controller parameters used in those applications, best engineering practices which rely on the design of experiments (DOE) or surface of responses is used. Generally, four PI controllers are used 
in a cascaded control scheme, where both of inner and outer loop deal with two PI controllers. Our earlier attempt was to use the response surface methodology (RSM) along with GA which could successfully determine optimum parameters for outer loop of the cascaded system [15]. However, the RSM can efficiently work with three or four design variables with minimum number of design experiments. An alternative way of thinking to solve these difficulties is proposed in this study using Taguchi method keeping the design experiments in the minimum number to speed up the tuning process.

Taguchi method is an optimization method, which has been applied to solve many optimization problems in electrical machines design and electric power systems [16]-[20]. It does not need to use sophisticated algorithms and extra programming beside the software tool used for system modeling [17]. For the same number of design variables and levels, Taguchi method gives a lower number of design experiments than that of the RSM [21], [22]. Therefore, time saving and lower cost can be achieved by using this method. A multi-objective design optimization is introduced to minimize the maximum percentage undershoot (MPUS), maximum percentage overshoot (MPOS), and the settling time $\left(T_{\mathrm{s}}\right)$ of the dynamic response. Optimum values of some design variables are determined by Taguchi method using analysis of means (ANOM). Analysis of variance (ANOVA) is used to select the other most influential design variables. The details of optimum design procedure for both Taguchi method and RSM-GA method which can handle eight design variables with the help of an orthogonal array are given. These methods are applicable to any cascaded control scheme used in other areas.

\section{BACKGROUND OF THE STUDY}

The penetration of renewable energy sources to the electrical power systems is increasing rapidly nowadays. The wind energy is becoming one of the mainstream power sources in many countries around the world. According to Global Wind Energy Council (GWEC) statistics, global wind power installations increased by $35.8 \mathrm{GW}$ in 2010 , bringing the total installed wind energy capacity up to $194.4 \mathrm{GW}$, a $22.5 \%$ increase on the 158.7 GW installed at the end of 2009 [23]. The total installed capacity of photovoltaic (PV) plants has increased over 36 times in the last 10 years (from $0.96 \mathrm{GW}$ in 2001 to $34.95 \mathrm{GW}$ in 2010) [24]. Other renewable energy sources such as tidal and marine current are also becoming popular. The use of power conversion system (PCS), for example, the DC-DC converter, AC-DC converter, and DC-AC inverter, is very common in the renewable energy conversion system. The grid connection schemes of variable-speed wind turbine driven permanent magnet synchronous generator (PMSG), doubly fed induction generator (DFIG), and PV system are shown in Fig. 1(a)-1(c), respectively. It is also required to utilize PCS in other renewable energy systems such as tidal and marine current.

Different types of energy storage systems such as superconducting magnetic energy storage (SMES) systems, energy capacitor systems (ECS), battery energy storage systems (BESS), and flywheel energy storage systems (FESS) are also using PCS nowadays due to the rapid development of power electronic industries [25], [26]. Besides, FACTS devices such
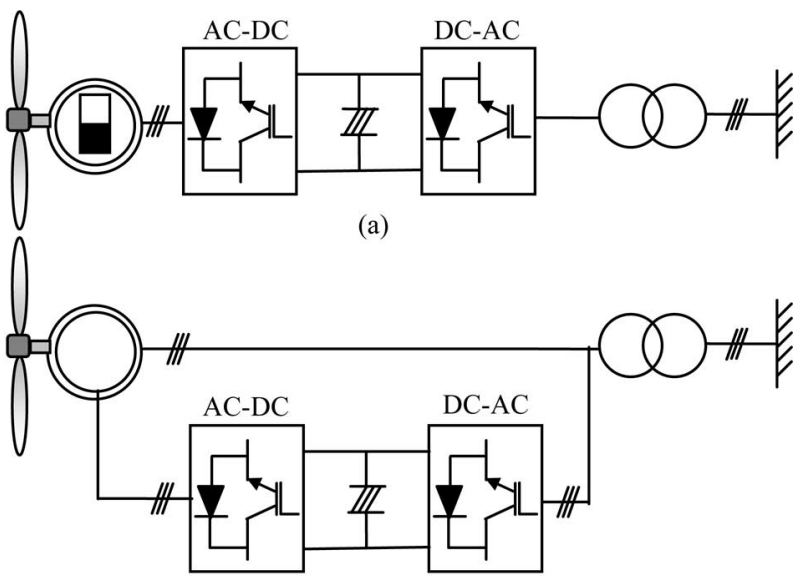

(b)

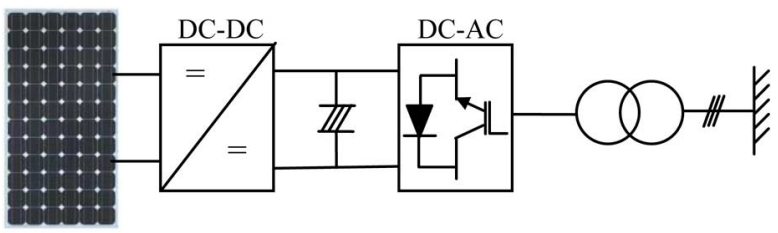

(c)

Fig. 1. Use of PCS in grid-connected renewable energy sector. (a) PMSG. (b) DFIG. (c) PV systems.

as SVC, STATCOM, dynamic voltage restorer (DVR), solid state transfer switch (SSTS), and unified power flow controller (UPFC) have been used for flexible power flow control, secure loading, and damping of the power system oscillations using PCS based on voltage or current source inverter technology [27]. Another potential area of PCS is in variable-speed drives. The PCS used in the aforementioned areas utilizes a cascaded control scheme which allows to bidirectional real and reactive power control abilities in the four-quadrant operation. Generally, the power electronic converter/inverter used in both machines (motor/generator) and/or the grid-side, shown in Fig. 1, uses four PI controllers in cascaded scheme as demonstrated schematically in Fig. 2. When the power converter is connected to the generator-side, the usual practice is to control the real and reactive power of the generator. In general, q-axis current of the generator is proportional to the active power and the $\mathrm{d}$-axis current is proportional to the reactive power. In the case of renewable energy system, the active power reference of the converter, $\mathrm{P}_{\mathrm{ref}}$, is determined in such a way to provide the maximum power to the grid from the renewable sources and the reactive power reference is set to zero to perform a unity power factor operation or to a threshold value to provide necessary reactive power support as in the case of DFIG control. In reference axis transformation (abc-to-dq and vice versa), the angle of the transformation is determined from the encoder using the rotor speed of the machine.

In the case of grid-side power inverter, the dc-link voltage can be controlled by the d-axis current and it is kept constant by setting a required dc-link reference voltage. On the other hand, the reactive power of the grid-side inverter can be controlled by the $\mathrm{q}$-axis current. The reactive power reference is set in such a way that the terminal voltage at the high voltage side of the transformer remains constant at 1.0 p.u. The grid synchronization 


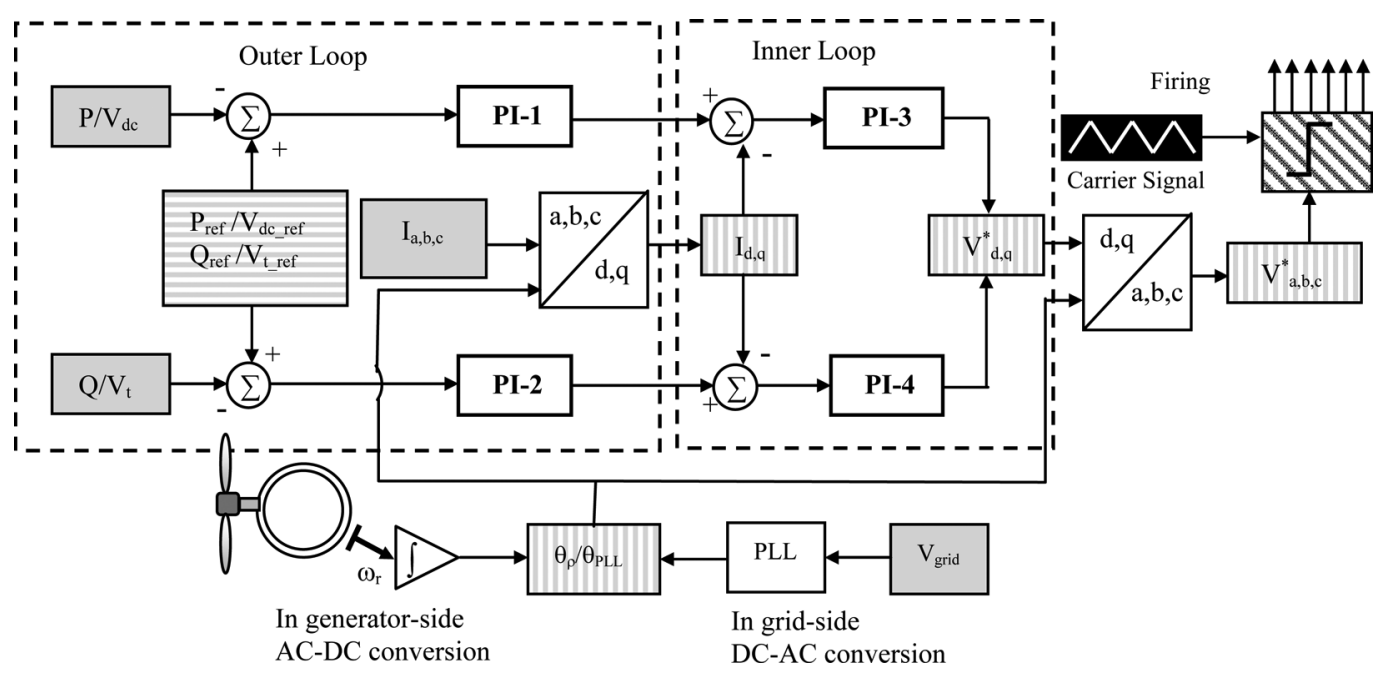

Fig. 2. Cascaded control scheme for both generator and grid-sides.

is maintained using the angle obtained from phase-lock-loop (PLL) which uses the grid-side three-phase voltages at the input of the PLL system [28].

In Fig. 2, the shaded rectangular blocks represent the actual or measured quantities. The block filled with vertical texture represent the calculated or processed values and block filled with horizontal texture represents the references or set points. In both outer and inner loops, there are two PI controllers which progress the error signals. The final outputs from the cascaded controller are the three-phase voltage references which generate the pulse width modulation (PWM) signals to drive the power electronic switches of the power converter.

In power system application, it is difficult to express the power converter units and its components through proper mathematical expressions or transfer functions considering different types of nonlinearity. Therefore, tuning four PI controllers in a cascaded control scheme is cumbersome, time consuming, and the case will be more difficult when multiple cascaded controller exists in one system such as the cases demonstrated in Fig. 1(a) and 1(b). Therefore, this study attempts to find a way to optimally design the cascaded controller parameters used in the PCS. The proposed method is to use a Taguchi approach to resolve the design optimization of four cascaded PI controller parameters, which have eight design variables. The proposed method is then compared with the RSM-GA method. It is noted that the RSM requires a lot of design experiments compared with Taguchi method. For example, for three-level four design variables, the RSM requires 31 design experiments to build the RSM model but in Taguchi method only nine experiments are required. However, the most popular statistical software programs can only handle up to five design variables to build the RSM model. Therefore, in this study, the RSM with the help of an orthogonal array is used to build the RSM model utilizing the same number of design experiments as used in Taguchi method.

\section{MODEL SYSTEM}

A renewable energy application is chosen to present the effectiveness of an optimum design of PI controllers used in cas- caded system. The model system shown in Fig. 1(a) is composed of a grid-connected variable-speed wind turbine (VSWT) driven PMSG using two back-to-back power converter units, where two set of cascaded controllers are being used. To focus on the design optimization more elaborately, only the grid-side inverter is demonstrated. The system base is 5 MVA. The generator data and other parameters are given in Appendix. The parameters of cascaded PI controllers are determined by the grid fault condition.

\section{Optimal Design of Cascade PI CONTROLLER USING TAGUCHI METHOD}

The design optimization process is presented in this study of fine tuning the PI controllers' parameters using Taguchi method. In Taguchi method, an orthogonal array that depends on the number of factors and their levels is used to study the parameters' variation effect [29]. This method has low number of experiments. For example, if there are four factors each at three levels, the full factorial design method requires $3^{4}=81$ experiments while Taguchi method needs only nine experiments to obtain the optimal values. In our study, one two-level factor and seven three-level factors are used. The full factorial design method requires $2^{1} * 3^{7}=4374$ designs to be considered while Taguchi method needs only 18 experiments to obtain optimal results.

\section{A. Orthogonal Array}

The design is explained in the light of cascaded control scheme shown in Fig. 2, where four PI controllers are used. In establishing an orthogonal array, eight factors A, B, C, D, E, F, G, and $\mathrm{H}$ are considered. A is the proportional gain of PI-1, $\mathrm{B}$ is the integral time constant of $\mathrm{PI}-1, \mathrm{C}$ is the proportional gain of PI-2, D is the integral time constant of PI-2, E is the proportional gain of $\mathrm{PI}-3, \mathrm{~F}$ is the integral time constant of $\mathrm{PI}-3, \mathrm{G}$ is the proportional gain of PI-4, and $\mathrm{H}$ is the integral time constant of PI-4. Table I illustrates the design variables or factors and their levels. The standard Taguchi's orthogonal array L-18 is used for this numerical experiments study as shown in Table II [16]. 
TABLE I

DESIGN VARIABLES AND LEVELS

\begin{tabular}{|c|c|c|c|}
\hline Design variable & Level 1 & Level 2 & Level 3 \\
\hline A & 2.5 & 4 & \\
\hline B & 0.4 & 0.6 & 0.8 \\
\hline C & 1.5 & 2 & 2.5 \\
\hline D & 0.4 & 0.6 & 0.8 \\
\hline E & 0.7 & 1 & 1.3 \\
\hline F & 0.008 & 0.0165 & 0.025 \\
\hline G & 0.1 & 0.3 & 0.5 \\
\hline H & 0.008 & 0.0165 & 0.025 \\
\hline
\end{tabular}

TABLE II

Actual Values of Settings of Eight Design Variables

\begin{tabular}{|c|c|c|c|c|c|c|c|c|}
\hline EXP. & \multicolumn{10}{|c|}{ LEVEL OF EACH VARIABLE } \\
\cline { 2 - 9 } No & $\mathrm{A}$ & $\mathrm{B}$ & $\mathrm{C}$ & $\mathrm{D}$ & $\mathrm{E}$ & $\mathrm{F}$ & $\mathrm{G}$ & $\mathrm{H}$ \\
\hline 1 & 2.5 & 0.4 & 1.5 & 0.4 & 0.7 & 0.008 & 0.1 & 0.008 \\
\hline 2 & 2.5 & 0.4 & 2 & 0.6 & 1 & 0.0165 & 0.3 & 0.0165 \\
\hline 3 & 2.5 & 0.4 & 2.5 & 0.8 & 1.3 & 0.025 & 0.5 & 0.025 \\
\hline 4 & 2.5 & 0.6 & 1.5 & 0.4 & 1 & 0.0165 & 0.5 & 0.025 \\
\hline 5 & 2.5 & 0.6 & 2 & 0.6 & 1.3 & 0.025 & 0.1 & 0.008 \\
\hline 6 & 2.5 & 0.6 & 2.5 & 0.8 & 0.7 & 0.008 & 0.3 & 0.0165 \\
\hline 7 & 2.5 & 0.8 & 1.5 & 0.6 & 0.7 & 0.025 & 0.3 & 0.025 \\
\hline 8 & 2.5 & 0.8 & 2 & 0.8 & 1 & 0.008 & 0.5 & 0.008 \\
\hline 9 & 2.5 & 0.8 & 2.5 & 0.4 & 1.3 & 0.0165 & 0.1 & 0.0165 \\
\hline 10 & 4 & 0.4 & 1.5 & 0.8 & 1.3 & 0.0165 & 0.3 & 0.008 \\
\hline 11 & 4 & 0.4 & 2 & 0.4 & 0.7 & 0.025 & 0.5 & 0.0165 \\
\hline 12 & 4 & 0.4 & 2.5 & 0.6 & 1 & 0.008 & 0.1 & 0.025 \\
\hline 13 & 4 & 0.6 & 1.5 & 0.6 & 1.3 & 0.008 & 0.5 & 0.0165 \\
\hline 14 & 4 & 0.6 & 2 & 0.8 & 0.7 & 0.0165 & 0.1 & 0.025 \\
\hline 15 & 4 & 0.6 & 2.5 & 0.4 & 1 & 0.025 & 0.3 & 0.008 \\
\hline 16 & 4 & 0.8 & 1.5 & 0.8 & 1 & 0.025 & 0.1 & 0.0165 \\
\hline 17 & 4 & 0.8 & 2 & 0.4 & 1.3 & 0.008 & 0.3 & 0.025 \\
\hline 18 & 4 & 0.8 & 2.5 & 0.6 & 0.7 & 0.0165 & 0.5 & 0.008 \\
\hline
\end{tabular}

TABLE III

RESULTS OF DYNAMIC RESPONSE ANALYSIS

\begin{tabular}{|c|c|c|c|}
\hline Exp. No. & MPUS (\%) & MPOS (\%) & Ts (s) \\
\hline 1 & 79.9 & 7.1 & 1.85 \\
\hline 2 & 77.4 & 6.9 & 2.3 \\
\hline 3 & 70.1 & 10 & 2.3 \\
\hline 4 & 80.3 & 8.9 & 1.9 \\
\hline 5 & 64.4 & 8.9 & 2.1 \\
\hline 6 & 68.7 & 4.3 & 2.0 \\
\hline 7 & 85.1 & 14.1 & 3.0 \\
\hline 8 & 57.8 & 9.6 & 1.9 \\
\hline 9 & 71.6 & 11.1 & 2.2 \\
\hline 10 & 67.3 & 12.3 & 2.5 \\
\hline 11 & 75.5 & 6.6 & 6 \\
\hline 12 & 69.7 & 8.3 & 2.4 \\
\hline 13 & 70.1 & 7.0 & 2.7 \\
\hline 14 & 80.5 & 10.5 & 2.8 \\
\hline 15 & 83.0 & 20 & 2.8 \\
\hline 16 & 83.7 & 7.3 & 3.1 \\
\hline 17 & 66.1 & 9.0 & 2.1 \\
\hline 18 & 62.2 & 9.0 & 2.5 \\
\hline
\end{tabular}

\section{B. Conduct the Experiment}

Eighteen experiments as shown in Table II should be carried out to obtain the dynamic response of the system with PI controllers at combination levels of these factors. The MPUS, MPOS, and $T_{s}$ of the terminal voltage of the grid are the most important variables. To obtain these values for each experiment, a PSCAD/EMTDC model of the system is used. Table III shows the simulation results for each experiment.

After performing the experiments and obtaining all experimental data, ANOM and ANOVA are carried out to estimate the
TABLE IV

MEAN OF RESULTS

\begin{tabular}{|c|c|c|c|}
\hline & MPUS (\%) & MPOS (\%) & $\mathrm{T}_{\mathrm{s}}(\mathrm{s})$ \\
\hline m (overall mean) & 72.96 & 9.49 & 2.58 \\
\hline
\end{tabular}

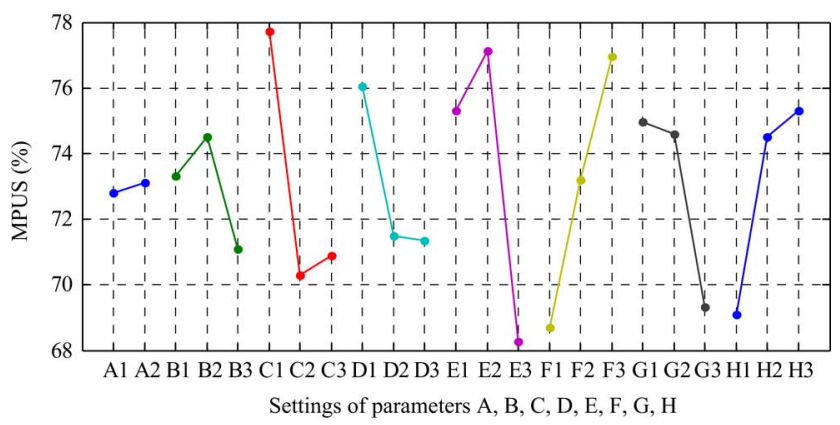

Fig. 3. Main factor effects on the MPUS.

effects of the design variables and determine the relative importance of each design variable, respectively [30].

\section{C. $A N O M$}

1) Overall Mean: The mean or average value of all results can be calculated as

$$
m=\frac{1}{18} \sum_{i=1}^{18} M P U S_{i} .
$$

Table IV shows the mean of MPUS, MPOS, and $\mathrm{T}_{\mathrm{s}}$.

2) Average Effect of a Design Variable at one Setting: The MPUS of factor B at level three is calculated by

$$
\begin{aligned}
m_{B 3}(M P U S)= & \frac{1}{6}(\operatorname{MPUS}(7)+\operatorname{MPUS}(8) \\
& +\operatorname{MPUS}(9)+\operatorname{MPUS}(16) \\
& +\operatorname{MPUS}(17)+\operatorname{MPUS}(18))
\end{aligned}
$$

where the factor B is set to level three only in experiments 7 to 9 and 16 to 18 . The MPUS for all levels for all factors can be determined by a similar way. The results are given in Table V. Fig. 3 shows main factor effects on the MPUS. It can be noticed that the factor-level combination $\left(\mathrm{A}_{1}, \mathrm{~B}_{3}, \mathrm{C}_{2}, \mathrm{D}_{3}, \mathrm{E}_{3}, \mathrm{~F}_{1}, \mathrm{G}_{3}, \mathrm{H}_{1}\right)$ contributes to the minimization of the MPUS. In a similar way, the MPOS and $\mathrm{T}_{\mathrm{s}}$ can be obtained for all levels of all factors. Tables VI and VII illustrate these results. In addition, Figs. 4 and 5 show main factor effects on the MPOS and $T_{s}$, respectively. Notably, the factor-level combination $\left(\mathrm{A}_{1}, \mathrm{~B}_{1}, \mathrm{C}_{2}, \mathrm{D}_{3}, \mathrm{E}_{1}, \mathrm{~F}_{1}, \mathrm{G}_{3}, \mathrm{H}_{2}\right)$ and $\left(\mathrm{A}_{1}, \mathrm{~B}_{2}, \mathrm{C}_{3}, \mathrm{D}_{3}, \mathrm{E}_{3}, \mathrm{~F}_{1}, \mathrm{G}_{1}, \mathrm{H}_{1}\right)$ contribute to the minimization of the MPOS and $T_{s}$, respectively. It can be shown that the factors $A_{1}, D_{3}$, and $F_{1}$ are the optimal values because they satisfy the design requirements (minimization of MPUS, MPOS, and $\mathrm{T}_{\mathrm{s}}$ ).

\section{ANOVA}

The previous figures that obtained by ANOM indicate the effect of design variables variation on the dynamic response of 


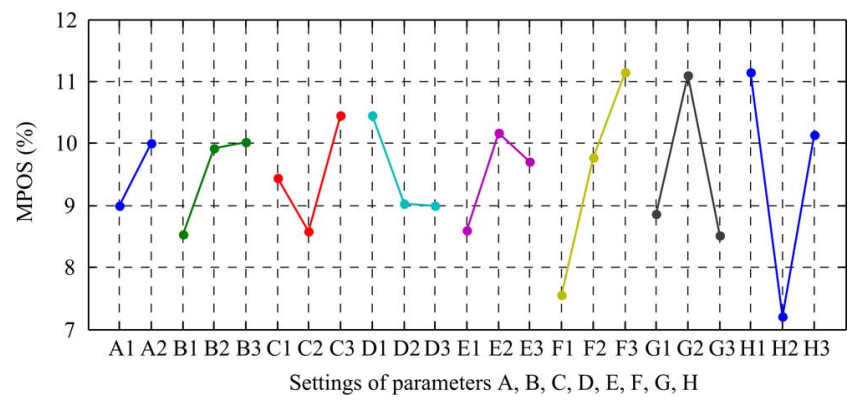

Fig. 4. Main factor effects on the MPOS.

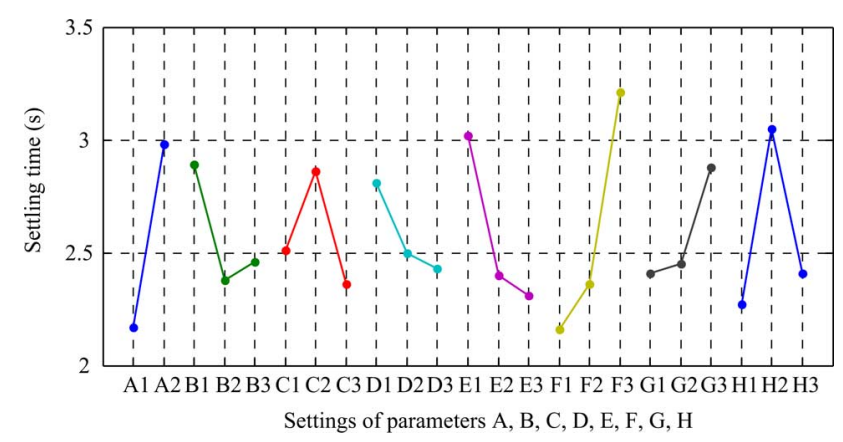

Fig. 5. Main factor effects on the $T_{s}$.

TABLE V

MPUS FOR ALL LEVELS OF ALL FACTORS

\begin{tabular}{|c|c|c|c|}
\hline Factors & Level 1 & Level 2 & Level 3 \\
\hline A & 72.81 & 73.12 & \\
\hline B & 73.31 & 74.5 & 71.08 \\
\hline C & 77.73 & 70.28 & 70.88 \\
\hline D & 76.06 & 71.48 & 71.35 \\
\hline E & 75.31 & 77.13 & 68.26 \\
\hline F & 68.71 & 73.21 & 76.96 \\
\hline G & 74.96 & 74.6 & 69.33 \\
\hline H & 69.1 & 74.5 & 75.3 \\
\hline
\end{tabular}

TABLE VI

MPOS FOR ALL LEVELS OF ALl FACTORS

\begin{tabular}{|c|c|c|c|}
\hline Factors & Level 1 & Level 2 & Level 3 \\
\hline A & 8.988 & 10 & \\
\hline B & 8.53 & 9.93 & 10.016 \\
\hline C & 9.45 & 8.58 & 10.45 \\
\hline D & 10.45 & 9.03 & 9 \\
\hline E & 8.6 & 10.166 & 9.71 \\
\hline F & 7.55 & 9.78 & 11.15 \\
\hline G & 8.86 & 11.1 & 8.51 \\
\hline H & 11.15 & 7.2 & 10.13 \\
\hline
\end{tabular}

TABLE VII

$T_{s}$ FOR ALL LEVELS OF ALL FACTORS

\begin{tabular}{|c|c|c|c|}
\hline Factors & Level 1 & Level 2 & Level 3 \\
\hline A & 2.17 & 2.98 & \\
\hline B & 2.89 & 2.38 & 2.46 \\
\hline C & 2.51 & 2.86 & 2.36 \\
\hline D & 2.81 & 2.5 & 2.43 \\
\hline E & 3.02 & 2.4 & 2.31 \\
\hline F & 2.16 & 2.36 & 3.21 \\
\hline G & 2.41 & 2.45 & 2.88 \\
\hline H & 2.27 & 3.05 & 2.41 \\
\hline
\end{tabular}

TABLE VIII

EFFECTS OF VARIOUS FACTORS ON THE DYNAMIC RESPONSE

\begin{tabular}{|c|c|c|c|c|c|c|}
\hline & \multicolumn{2}{|c|}{ MPUS } & \multicolumn{2}{c|}{ MPOS } & \multicolumn{2}{c|}{$\mathrm{T}_{\mathrm{s}}$} \\
\cline { 2 - 7 } & SSF & $\begin{array}{c}\text { Factor } \\
\text { Effects } \\
(\%)\end{array}$ & SSF & $\begin{array}{c}\text { Factor } \\
\text { Effects } \\
(\%)\end{array}$ & SSF & $\begin{array}{c}\text { Factor } \\
\text { Effects } \\
(\%)\end{array}$ \\
\hline B & 18.065 & 4.7 & 4.17 & 8.28 & 0.445 & 13.97 \\
\hline C & 102.78 & 26.79 & 5.25 & 10.42 & 0.398 & 12.48 \\
\hline G & 59.613 & 15.53 & 11.85 & 23.5 & 0.415 & 13 \\
\hline E & 134.93 & 35.17 & 3.9 & 7.73 & 0.9 & 28.5 \\
\hline H & 68.24 & 17.78 & 25.24 & 50 & 1.02 & 32 \\
\hline Sum & 383.63 & 100 & 50.41 & 100 & 3.19 & 100 \\
\hline
\end{tabular}

TABLE IX

OPTIMUM LEVEL AND VALUE

\begin{tabular}{|c|c|c|c|c|c|c|c|c|}
\hline $\begin{array}{c}\text { Design } \\
\text { variables } \\
\text { Levels }\end{array}$ & $A$ & $B$ & $C$ & $D$ & $E$ & $F$ & $G$ & $H$ \\
\hline $\begin{array}{c}\text { Optimum } \\
\text { level }\end{array}$ & $A_{1}$ & $B_{2}$ & $C_{2}$ & $D_{3}$ & $E_{3}$ & $F_{2}$ & $G_{3}$ & $H_{2}$ \\
\hline $\begin{array}{c}\text { Optimum } \\
\text { value }\end{array}$ & 2.5 & 0.6 & 2 & 0. & 1.3 & 0.008 & $\begin{array}{c}0 . \\
5\end{array}$ & $\begin{array}{c}0.016 \\
5\end{array}$ \\
\hline
\end{tabular}

PMSG-VSWT system. Furthermore, ANOVA is used to determine the relative importance of the various design variables. To perform ANOVA, the sum of squares (SS) should be calculated. The sum of squares of factor B (SSFB) can be computed as follows:

$$
S S F B=3 \sum_{i=1}^{3}\left(m_{B i}-m\right)^{2} .
$$

SSFC, SSFG, SSFE, and SSFH can be obtained by using the same way. Table VIII presents these results.

It can be seen in Table VIII that the effect of factor B on $T_{s}$ is comparatively larger than that of MPUS and MPOS. Therefore, the factor $\mathrm{B}_{2}$ represents its optimal value. In addition, the factors $\mathrm{C}$ and $\mathrm{E}$ have greater effect notably on MPUS than that of MPOS and $\mathrm{T}_{\mathrm{s}}$. Therefore, their optimal values are $\mathrm{C}_{2}$ and $\mathrm{E}_{3}$, respectively. Moreover, the factors $\mathrm{G}$ and $\mathrm{H}$ have greater effect notably on MPOS than that of MPUS and $\mathrm{T}_{\mathrm{s}}$. Therefore, their optimal values are $\mathrm{G}_{3}$ and $\mathrm{H}_{2}$, respectively. The optimum level and value of each design variable are listed in Table IX. The dynamic response of the system with these optimally designed PI controllers should be verified with the simulation results using PSCAD/EMTDC model.

\section{Optimal Design by RSM-GA Method}

The RSM is a statistical tool used to build an empirical model by finding the relationship between the design variables and response through statistical fitting method [21]. The system analysis on laboratory standard power system simulation package PSCAD/EMTDC [31] is used as numerical simulations to provide the response as shown in Table III. The MPUS $\left(Y_{1}\right)$, MPOS $\left(Y_{2}\right)$, and $\mathrm{T}_{\mathrm{s}}\left(Y_{3}\right)$ of the voltage profile are considering the responses. Those are changed by the design variables variant. The second-order model of the RSM is used in this study in terms of eight design variables for obtaining the responses [32]. The creation of response surface is based on the central composite design (CCD), which has been widely used for fitting the second-order response surface [15], [21]. 


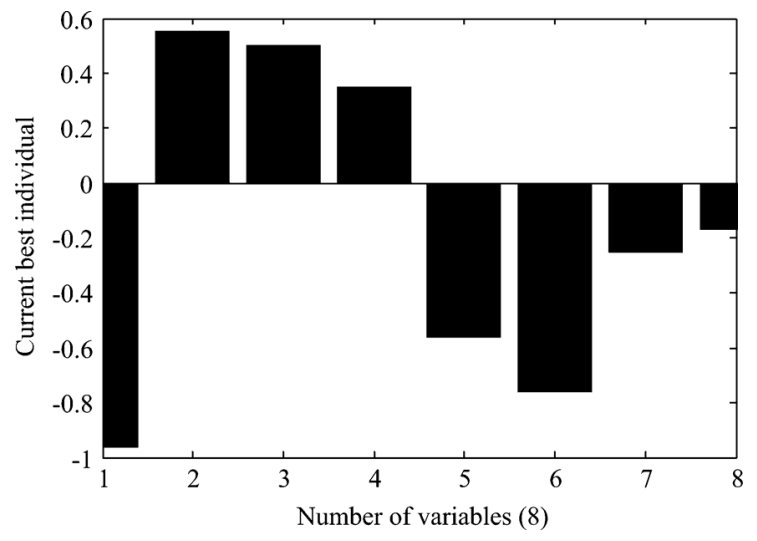

Fig. 6. Current best individual.

The three fitted second-order polynomial functions are written as follows:

$$
\begin{aligned}
Y_{1}= & 76.1+0.1556 x_{1}-1.1167 x_{2}-3.425 x_{3} \\
& -2.3583 x_{4}-3.525 x_{5}+4.125 x_{6}-2.8167 x_{7} \\
& +3.1 x_{8}-2.3 x_{2}^{2}+4.025 x_{3}^{2}+2.225 x_{4}^{2} \\
& -3.525 x_{5}^{2}-0.375 x_{6}^{2} \\
& -2.45 x_{7}^{2}-2.3 x_{8}^{2}+1.0333 x_{1} x_{2} \\
Y_{2}= & 10.65-0.0722 x_{1}+1.2972 x_{2}+4.0278 x_{3} \\
& +1.925 x_{4}+0.2181 x_{5}+3.4278 x_{6}+0.9819 x_{7} \\
& +1.8417 x_{8}-4.11 x_{5}^{2}+2.379 x_{7}^{2}-1.613 x_{1} x_{2} \\
& +3.916 x_{2} x_{7}+7.05 x_{2} x_{8}-1.52 x_{3} x_{4}-0.2 x_{3} x_{5} \\
& +3.75 x_{3} x_{6} \\
Y_{3}= & 3.07+0.836 x_{1}-0.152 x_{2}-1.273 x_{3}-0.964 x_{4} \\
& -0.441 x_{5}-0.133 x_{6}-0.245 x_{7}-0.647 x_{8} \\
& +1.1 x_{5}^{2}-1.84 x_{7}^{2}-0.38 x_{1} x_{2}-1.255 x_{2} x_{7} \\
& -2.4 x_{2} x_{8}+0.57 x_{3} x_{4}+0.71 x_{3} x_{5}-0.33 x_{3} x_{6} .
\end{aligned}
$$

A multi-objective GA works directly on this model and MATLAB optimization Toolbox is considered for this study [33]. The optimal target is to minimize the MPUS of voltage profile as well as minimizing MPOS and $\mathrm{T}_{\mathrm{s}}$. The constraints of the optimized problem are described as follows:

- Design variables range is $2.5 \leq X_{1}, 0.4 \leq X_{2} \leq 0.8$, $1.5 \leq X_{3} \leq 2.5,0.4 \leq X_{4} \leq 0.8,0.7 \leq X_{5} \leq 1.3$, $0.008 \leq X_{6} \leq 0.025,0.1 \leq X_{7} \leq 0.5$ and $0.008 \leq$ $X_{8} \leq 0.025$.

Table X shows GA characteristics. After the 7th iteration, GA optimization was terminated; where average change in the fitness functions values were less than 1e-6. Fig. 6 shows the current best individual. Table XI shows the optimal level and the size value of all the design variables. At these optimal values, the MPUS equals $70.05 \%$, the MPOS is $7.28 \%$, and $\mathrm{T}_{\mathrm{s}}$ is $2.85 \mathrm{~s}$.

\section{Simulation Results}

Time domain simulation has been carried out using PSCAD/ EMTDC. The time step is chosen $0.00001 \mathrm{~s}$. It is assumed that
TABLE X

GA CHARACTERISTICS

\begin{tabular}{|c|c|}
\hline \multicolumn{2}{|c|}{ GA Parameters } \\
\hline Population type & Double vector \\
\hline Population size & 20 \\
\hline Fitness scaling function & Rank \\
\hline Selection function & Uniform \\
\hline Crossover fraction & 0.8 \\
\hline Crossover function & Scattered \\
\hline Migration fraction & 0.2 \\
\hline Migration interval & 20 \\
\hline
\end{tabular}

TABLE XI

Optimal LeVEl and Size OF DeSIGN VARIABLes Using GA

\begin{tabular}{|c|c|c|c|c|c|c|c|c|}
\hline $\begin{array}{c}\text { Design } \\
\text { variables } \\
\text { Level }\end{array}$ & $\mathrm{X}_{1}$ & $\mathrm{X}_{2}$ & $\mathrm{X}_{3}$ & $\mathrm{X}_{4}$ & $\mathrm{X}_{5}$ & $\mathrm{X}_{6}$ & $\mathrm{X}_{7}$ & $\mathrm{X}_{8}$ \\
\hline $\begin{array}{c}\text { Optimum } \\
\text { level }\end{array}$ & -0.96 & 0.55 & 0.5 & 0.35 & -0.56 & -0.76 & -0.25 & -0.17 \\
\hline $\begin{array}{c}\text { Optimum } \\
\text { size }\end{array}$ & 2.53 & 0.71 & 2.25 & 0.67 & 0.83 & 0.01 & 0.25 & 0.015 \\
\hline
\end{tabular}

the wind speed is constant and equal to the rated speed. This is because it may be considered that wind speed does not change dramatically during the short time interval of the simulation for the transient or a fault ride through characteristics analysis.

Due to the huge penetration of wind power to the grid, many countries are imposing new grid codes nowadays to secure the power system operations. The wind farm grid code is fairly important to analyze the transient characteristics of the wind turbine generation system (WTGS). As mentioned earlier, in this study, an optimum design of cascaded PI controllers' parameters is determined by the grid fault condition. The grid code is taken into consideration to evaluate the performance of grid-side power inverter using the PI controllers' parameters obtained from Taguchi or RSM-GA approaches. In this study, the simulation results are described in the light of recent grid code, set by E. On Netz, this is recently known as TenneT TSO GmbH. As per the grid code, the terminal voltage should recover within $90 \%$ of the prefault value in $1.5 \mathrm{~s}$ from the fault occurrence [34].

In simulation analysis, the severe symmetrical three-line to ground fault (3LG) is considered as the network disturbance. The fault occurs at $0.1 \mathrm{~s}$ at the sending end of the transmission line, immediately after the transformer shown in Fig. 1(a). The double circuit transmission line is considered and the circuit breakers (CBs) on the faulted line are opened at $0.25 \mathrm{~s}$, and at $1.05 \mathrm{~s}$ the $\mathrm{CBs}$ are reclosed.

The responses of the grid-side terminal voltage using the cascaded parameters obtained from Taguchi and RSM-GA method is shown together in Fig. 7. Both of the approaches can augment the fault ride through capability of the wind generator as per recent grid code. Other responses such as the real and reactive power of the grid-side power inverter are shown in Figs. 8 and 9, respectively, for both approaches. The rotor speed responses, shown in Fig. 10, indicate that the PMSG maintains the stability even in a severe $3 \mathrm{LG}$ fault. The dc-link voltage responses using both Taguchi and RSM-GA method is shown in Fig. 11. Notably, a dc-link over voltage protection scheme using braking chopper is considered in the simulation to keep 


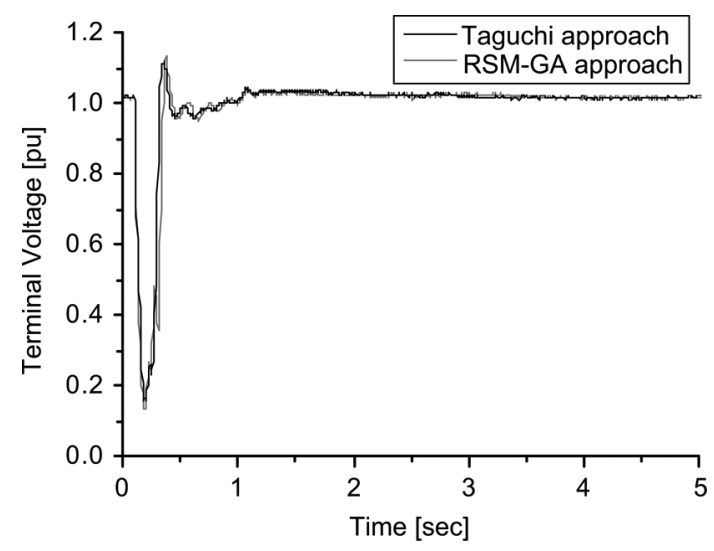

Fig. 7. Grid-side terminal voltage.

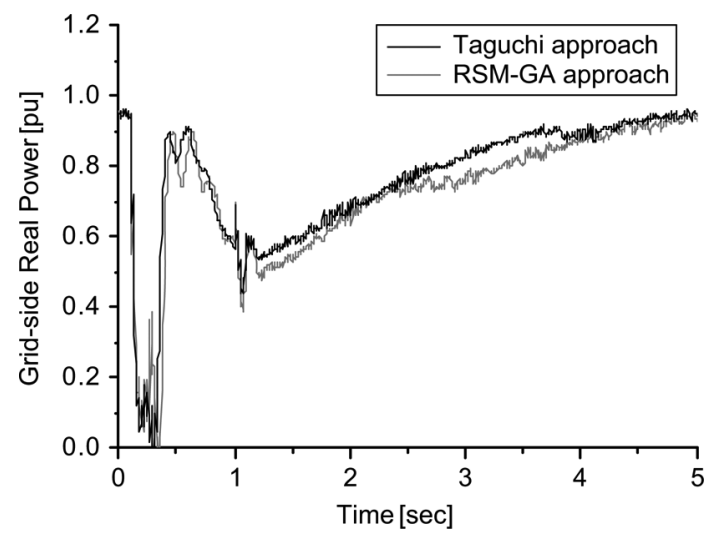

Fig. 8. Real power of the grid-side power inverter.

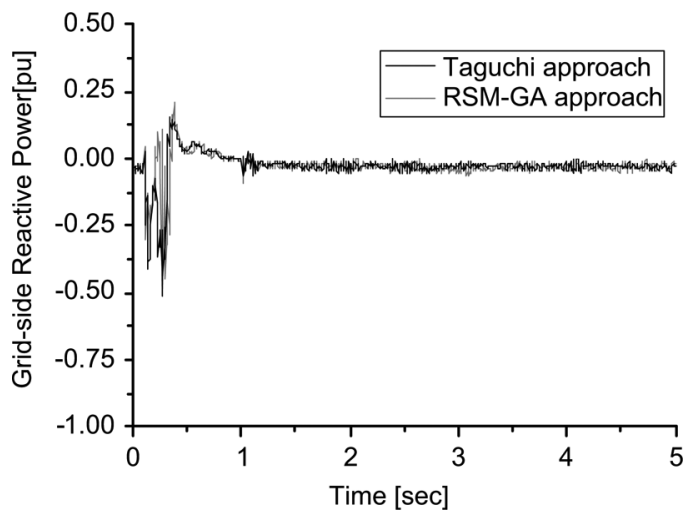

Fig. 9. Reactive power of the grid-side power inverter.

the dc-link voltage within an acceptable range. The response of the current through braking chopper is shown in Fig. 12.

It is found from the simulation results that both Taguchi and RSM-GA approach is a good method to design eight design variables of four PI controllers in a cascaded control scheme. However, it is shown that Taguchi approach gives better response in terms of fast voltage recovery as per grid code requirement. It also gives lower oscillations as obvious from the responses.

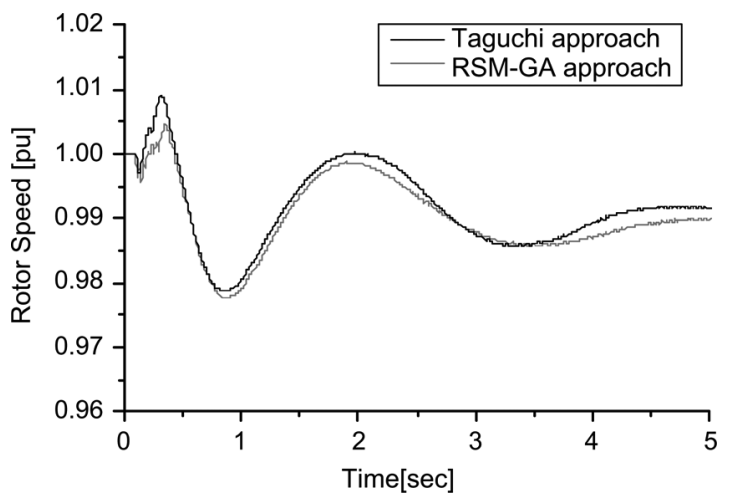

Fig. 10. Rotor speed of PMSG.

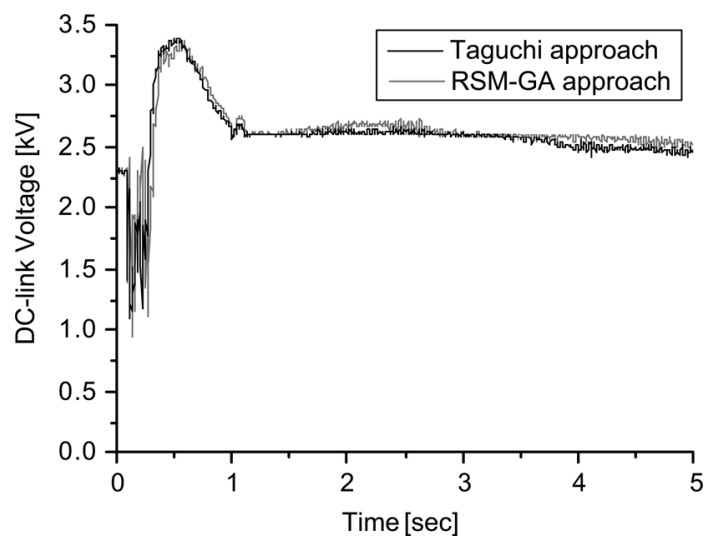

Fig. 11. DC-link voltage.

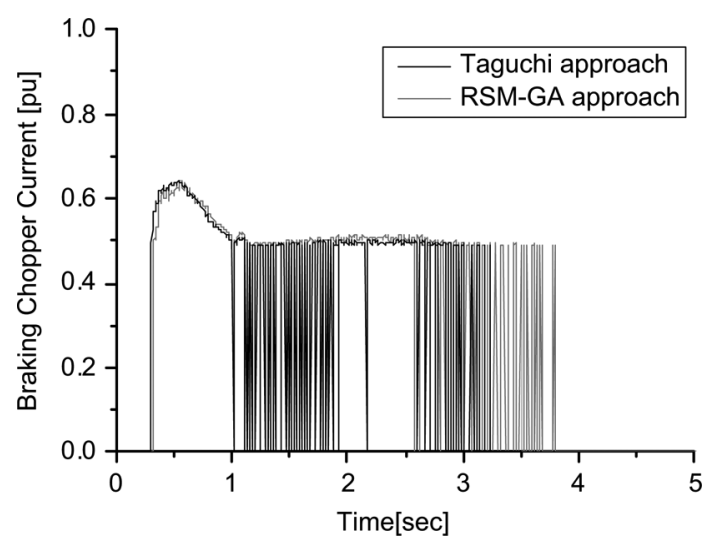

Fig. 12. Current in the braking chopper.

\section{CONCLUSION}

In this study, an optimum design procedure for a cascaded control scheme using multiple PI controllers has been presented based on Taguchi approach. The results have been compared with an alternate design procedure based on the RSM-GA approach. Both methods have been tested in the same renewable energy application, where a cascaded control scheme is used in the operation of a grid-connected variable-speed wind turbine driven permanent magnet synchronous generator. The effectiveness of the design procedures in a cascaded control scheme using both design approaches has been verified under the grid 
TABLE XII

Generator Parameters. Double Circuit Transmission Line PARAMETERS: $\mathrm{R}+\mathrm{j} \mathrm{X}=0.1+\mathrm{j} 0.6$ p.11.. LEAKAGE REACTANCE OF TRANSFORMER $=0.1$ P.U. TRANSFORMER VOLTAGE RATIO $=1.25 / 11.4 \mathrm{KV}$

\begin{tabular}{|l|l|l|l|}
\hline Rated Power & $5[\mathrm{MW}]$ & Stator Resistance & $0.01[\mathrm{pu}]$ \\
\hline Rated Voltage & $1.0[\mathrm{kV}]$ & d-axis Reactance & $1.0[\mathrm{pu}]$ \\
\hline Frequency & $20[\mathrm{~Hz}]$ & q-axis Reactance & $0.7[\mathrm{pu}]$ \\
\hline Number of Poles & 150 & Field Flux & $1.4[\mathrm{pu}]$ \\
\hline H & $3.0[\mathrm{~s}]$ & & \\
\hline
\end{tabular}

fault condition. The conclusion and observations are summarized as follows:

1) Both Taguchi and RSM-GA approach can successfully be used to fine tune eight design variables of four PI controllers simultaneously in a cascaded scheme. In both approaches only 18 design experiments have been used.

2) However, the transient responses obtained using Taguchi approach is found better than that obtained using the RSM-GA. The reason might be of using L18 orthogonal array to build the RSM model.

3) It might be possible to obtain a better response using the RSM-GA approach. However, the required number of design experiments is much larger than that of Taguchi method. It is noted that the software used for developing the well-known RSM model can handle up to five design variables which requires 52 design experiments. Therefore, to handle eight design variables in a cascaded control scheme, the RSM model which built with the help of an orthogonal array, is found to be the best option.

4) Taguchi approach facilitates a multi-objective design optimization, which may give additional design flexibility in some applications. Finally, it is concluded that Taguchi approach is a good method for optimum design of multiple variables of PI controllers used in a cascaded control scheme. The proposed procedure is applicable to any cascaded control scheme in the areas of renewable energy, energy storage systems, variable-speed drives, and FACTS devices used in the power systems, and many more.

\section{APPENDIX}

Table XII lists the generator parameters.

\section{REFERENCES}

[1] K. J. Astrom and T. Hagglund, "The future of PID control," Control Eng. Practice, vol. 9, no. 11, pp. 1163-1175, 2001.

[2] A. Visioli, "Tuning of PID controllers with fuzzy logic," IEE Proc. Control Theory Appl., vol. 148, no. 1, pp. 1-8, Jan. 2001.

[3] Y. Li, K. H. Ang, and G. C. Y. Chong, "PID control system analysis and design, problems, remedies, and future directions," IEEE Control Syst. Mag., vol. 26, no. 1, pp. 32-41, 2006.

[4] S.-R. Qi, D.-F. Wang, P. Han, and Y. -H. Li, "Grey prediction based RBF neural network self-tuning pid control for turning process," in Proc. Int. Conf. Machine Learning and Cybernetics, Shanghai, China, 2004, pp. 802-805.

[5] A. Rubaai, M. J. Castro-Sitiriche, and A. R. Ofoli, "Design and implementation of parallel fuzzy PID controller for high-performance brushless motor drives: An integrated environment for rapid control prototyping," IEEE Trans. Ind. Appl., vol. 44, no. 4, pp. 1090-1098, Jul./Aug. 2008.

[6] A. Rubaai and P. Young, "EKF-based PI-/PD-like fuzzy-neural-network-controller for brushless drives," IEEE Trans. Ind. Appl., vol. 47, no. 6, pp. 2391-2401, Nov./Dec. 2011.

[7] B. Lennartson and B. Kristiansson, "Evaluation and tuning of robust PID controllers," IET Control Theory Appl., vol. 3, no. 3, pp. 294-302, 2009.
[8] X. H. Li, H. B. Yu, M. Z. Yuan, and J. Wang, "Design of robust optimal proportional-integral-derivative controller based on new interval polynomial stability criterion and Lyapunov theorem in the multiple parameters' perturbations circumstance," IET Control Theory Appl., vol. 4, no. 11 , pp. 2427-2440, 2010.

[9] R. A. Krohling and J. P. Rey, "Design of optimal disturbance rejection pid controllers using genetic algorithms," IEEE Trans. Evol. Computat., vol. 5, no. 1, pp. 78-82, Feb. 2001.

[10] D. Devaraj and B. Selvabala, "Real-coded genetic algorithm and fuzzy logic approach for real-time tuning of proportional-integral-derivative controller in automatic voltage regulator system," IET Gen., Transm., Distrib., vol. 3, no. 7, pp. 641-649, 2009.

[11] J. Zhang, J. Zhuang, H. Du, and S. Wang, "Self-organizing genetic algorithm based tuning of PID controllers," Inf. Sci., vol. 179, no. 7, pp. 1007-1018, Mar. 2009.

[12] Z.-L. Gaing, "A particle swarm optimization approach for optimum design of pid controller in AVR system," IEEE Trans. Energy Convers., vol. 19, no. 2, pp. 384-391, Jun. 2004.

[13] V. Mukherjee and S. P. Ghoshal, "Intelligent particle swarm optimized fuzzy PID controller for AVR system," Elect. Power Syst. Res., vol. 77, pp. 1689-1698, 2007.

[14] J. Shian Chiou and M.-T. Liu, "Numerical simulation for fuzzy PID controllers and helping EP reproduction with PSO hybrid algorithm," Simulat. Model. Practice Theory, vol. 17, no. 10, pp. 1555-1565, Nov. 2009.

[15] H. M. Hasanien and S. M. Muyeen, "Design optimization of controller parameters used in variable-speed wind energy conversion system by genetic algorithms," IEEE Trans. Sustain. Energy, vol. 3, no. 2, pp. 200-208, Apr. 2012.

[16] A. M. Omekanda, "Robust torque and torque-per-inertia optimization of a switched reluctance motor using the Taguchi methods," IEEE Trans. Ind. Appl., vol. 42, no. 2, pp. 473-478, Mar./Apr. 2006.

[17] C.-C. Hwang, L.-Y. Lyu, C.-T. Liu, and P. -L. Li, "Optimal design of an SPM motor using genetic algorithms and Taguchi method," IEEE Trans. Magn., vol. 44, no. 11, pp. 4325-4328, Nov. 2008.

[18] M. Ashabani, Y. A.-R. I. Mohamed, and J. Milimonfared, "Optimum design of tubular permanent magnet motors for thrust characteristics improvement by combined Taguchi-neural network approach," IEEE Trans. Magn., vol. 46, no. 12, pp. 4092-4100, Dec. 2010.

[19] F. Desta Zahaly, K. S. Rama Rao, and T. B. Ibrahim, "A new intelligent autoreclosing scheme using artificial neural network and Taguchi's methodology," IEEE Trans. Ind. Appl., vol. 47, no. 1, pp. 306-313, Jan./Feb. 2010.

[20] Y.-H. Liu and Y.-F. Luo, "Search for an optimal rapid-charging pattern for li-ion batteries using the Taguchi approach," IEEE Trans. Ind. Electron., vol. 57, no. 12, pp. 3963-3971, Dec. 2010.

[21] H. M. Hasanien, A. S. Abd-Rabou, and S. M. Sakr, "Design optimization of transverse flux linear motor for weight reduction and performance improvement using response surface methodology and genetic algorithms," IEEE Trans. Energy Convers., vol. 25, no. 3, pp. 598-605, Sep. 2010.

[22] H. M. Hasanien, "Particle swarm design optimization of transverse flux linear motor for weight reduction and improvement of thrust force," IEEE Trans. Ind. Electron., vol. 58, no. 9, pp. 4048-4056, Sep. 2011.

[23] , S. M. Muyeen, Ed., Wind Energy Conversion Systems: Technology and Trends. London, U.K.: Springer-Verlag, 2012.

[24] Trends in Photovoltaic Applications-Survey Report of Selected IEA Countries Between 1992 and 2010. [Online]. Available: http://www. iea-pvps.org/.

[25] S. M. Muyeen, J. Tamura, and T. Murata, Stability Augmentation of a Grid-Connected Wind Farm. London, U.K.: Springer-Verlag, 2008.

[26] S. M. Muyeen, H. M. Hasanien, and J. Tamura, "Reduction of frequency fluctuation for wind farm connected power systems by an adaptive artificial neural network controlled energy capacitor system," IET Renew. Power Gen., vol. 6, no. 4, pp. 226-235, Jul. 2012.

[27] Y. -H. Song and A. T. Johns, Flexible AC Transmission Systems (FACTS). London, U.K.: Inst. Elect. Engineers, 1999.

[28] H. M. Hasanien and S. M. Muyeen, "Speed control of grid-connected switched reluctance generator driven by variable speed wind turbine using adaptive neural network controller," Elect. Power Syst. Res., Elsevier, vol. 84, no. 1, pp. 206-213, Mar. 2012.

[29] R. K. Roy, Design of Experiments Using the Taguchi Approach. New York: Wiley-Interscience, 2001.

[30] C.-C. Hwang, L.-Y. Lyu, C.-T. Liu, and P.-L. Li, "Optimal design of an SPM motor using genetic algorithms and Taguchi method," IEEE Trans. Magn., vol. 44, no. 11, pp. 4325-4328, Nov. 2008.

[31] PSCAD/EMTDC Manual, Manitoba HVDC Research Center, 1994.

[32] P. Mathews, Design of Experiments With MINITAB, American Society of Quality. Milwaukee, WI: Quality Press, 2005. 
[33] Release 2010 b, MATLAB Optimization Toolbox, The Math Works press, 2010.

[34] E. O. Netz, Grid Code, High and Extra-High Voltage, Apr. 2006. [Online]. Available: http://www.eon-netz.com/.

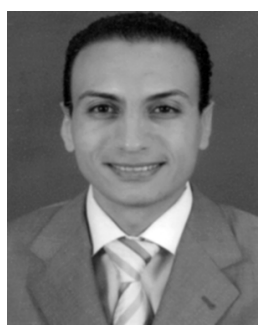

Hany M. Hasanien (M'09-SM'11) was born in Cairo, Egypt, on May 20, 1976. He received the B.Sc., M.Sc. and Ph.D degrees in electrical engineering from Ain Shams University, Faculty of Engineering, Cairo, Egypt, in 1999, 2004, and 2007, respectively.

$\mathrm{He}$ is an Associate Professor at the Electrical Power and Machines Department, Faculty of Engineering, Ain Shams University. Currently, he is on leave as an Assistant Professor at the Electrical Engineering Department, College of Engineering,

King Saud University. His research interests include electrical machines design, modern control techniques, electrical drives, and artificial intelligence applications on electrical machines and renewable energy systems. He has authored, co-authored, and edited 3 books in the areas of electric machines and renewable energy.

Dr. Hasanien is a Senior member of the Power \& Energy Society (PES). His biography has been included in Marquis Who's Who in the world for its 28th edition, 2011.

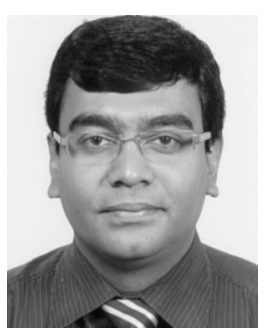

S. M. Muyeen (S'03-M'08-SM'12) received the B.Sc. Eng. degree from Rajshahi University of Engineering and Technology (RUET), Bangladesh, formerly known as Rajshahi Institute of Technology, in 2000 and the M.Sc. Eng. and Dr. Eng. degrees from Kitami Institute of Technology, Japan, in 2005 and 2008, respectively, all in electrical and electronic engineering. His $\mathrm{Ph} . \mathrm{D}$. research work focused on wind farm stabilization from the viewpoint of LVRT and frequency fluctuation.

After completing his Ph.D. program, he worked as a Postdoctoral Research Fellow under the versatile banner of Japan Society for the Promotion of Science (JSPS) from 2008-2010 at the Kitami Institute of Technology, Japan. At the present, he is working as an Assistant Professor in the Electrical Engineering Department at the Petroleum Institute, Abu Dhabi. His research interests are power system stability and control, electrical machine, FACTS, energy storage system (ESS), renewable energy, and HVDC system. He has authored, co-authored, and edited 4 books in the areas of electric machines and renewable energy. 